\title{
Management and Outcome of Uveal Melanoma in a Single Tertiary Cancer Center in Jordan
}

\author{
Ahmed ZEWAR ${ }^{1}$, Ibrahim NAWAISEH ${ }^{1}$, Imad JARADAT ${ }^{2}$, Jakub KHZOUZ ${ }^{3}$, Khaleel ALRAWASHDEH ${ }^{1}$, \\ Ghadeer ABDEEN ${ }^{4}$, Mustafa MEHYAR', Samer KHURMA', Yacoub A YOUSEF ${ }^{1}$
}

Departments of 'Ophthalmology, ${ }^{2}$ Radiotherapy, ${ }^{3}$ Pathology and ${ }^{4}$ Medical Oncology, King Hussein Cancer Centre (KHCC), AMMAN, JORDAN

\begin{abstract}
Objective: The aim of this study was evaluate the features and outcome of management of uveal melanoma in King Hussein Cancer Center as an example of a referral tertiary cancer center in the Middle East.

Material and Method: This was aetrospective, observational case series of 46 eyes of 46 patients with uveal melanoma. Data collection required access to medical records, radiology and pathology reports, and laboratory results. The main outcome measures included age at diagnosis, tumor location and dimensions, TNM stage, treatment modality, visual outcome, metastasis, and mortality.

Results: There was slight female preference, and the median age at diagnosis was 45 years. Eighteen (39\%) eyes were treated by primary enucleation, and 28 (61\%) eyes were treated by I-125 radioactive plaque. The melanoma was in the choroid in 40 (87\%) eyes and in the ciliary body in 6 (13\%) eyes, with no single tumor in the iris. According to the 7th edition of the American Joint Committee on Cancer staging system (UICC/AJCC); 8 (17\%) were T1, 17 (36\%) were T2, 16 (35\%) were T3, and $5(11 \%)$ were T4. One (2\%) patient showed lymph node metastasis (N1), and 6 (13\%) patients showed distant metastasis (M1). Pathologically, 2 (10\%) of the enucleated eyes were spindle cell type, 4 (20\%) were epithelioid cell type, and 14 (70\%) were mixed type. Extrascleral extension was seen in three (15\%) eyes, and optic nerve invasion in two (10\%) eyes. After brachytherapy, 26 (93\%) eyes were salvaged, and 2 eyes were consecutively enucleated; one for tumor recurrence, and one for uncontrolled painful neovascular glaucoma. The eye salvage rate post plaque was $93 \%(26 / 28)$, and the visual acuity for the salvaged eyes was equal or better than 0.5 in 11 (42\%) eyes, 0.1-0.4 in 5 (19\%) eyes, and less than 0.1 in 10 (38\%) eyes.
\end{abstract}

Conclusion: The incidence of uveal melanomas in our region is low compared to that in the West with a younger age at presentation. Candidate tumors for radioactive plaque therapy were successfully controlled in $93 \%$ of cases

Key Words: Choroid, Enucleation, Melanoma, Radioactive plaque therapy

\section{INTRODUCTION}

Uveal melanoma is the most common primary intraocular malignancy in adults and accounts for $5 \%$ of all melanomas (1). It is seen more frequently in Caucasians in comparison with Hispanics, Asians and Africans. For the Whites in the United States, uveal melanoma has an incidence of 0.69 and 0.54 per 100,000 person-year for males and females consecutively with a mean age of 60 (1).

Uveal melanoma mostly appears in the choroid (85-91\% of cases), and it is localized to the ciliary body or the iris in $9-15 \%$ of cases (2). Iris melanomas are associated with the earliest detection and overall best prognosis while ciliary body melanomas are associated with the worst prognosis $(3,4)$.Around $50 \%$ of patients diagnosed with uveal melanoma will develop metastasis, despite treatment, with survival time after metastasis averaging 6-12 months $(5,6)$.

(Turk Patoloji Derg 2016, 32:186-192)

Received : 31.12.2015 Accepted : 18.03.2016
The Collaborative Ocular Melanoma Study (COMS) concluded that there was no significant difference between brachytherapy and enucleation in terms of prevention of metastasis and mortality for medium sized melanomas. Globe and vision-preserving radiation therapy is therefore currently the primary treatment of choice for most uveal melanomas in the developed world $(1,7,8)$.

There is limited data about the features and outcome of management of uveal melanoma in the Middle East in general and in Jordan specifically. The aim of this study is to describe the features and outcome of uveal melanoma management in a single tertiary cancer center in Jordan (King Hussein Cancer Center (KHCC), Amman, Jordan) in a developing country in the Middle East.

Correspondence: Yacoub A YOUSEF

Departments of Ophthalmology, King Hussein Cancer Centre (KHCC),

AMMAN, JORDAN

E-mail: yyousef@khcc.jo Phone: +962 65300460 


\section{MATERIAL and METHODS}

This study was approved by the Institutional Review Board in KHCC. It was a retrospective case series of 46 eyes of 46 consecutive patients from July 2006 to April 2014 who had intraocular uveal melanoma. Selection required access to patients' medical charts, pathologic records, radiology reports, and laboratory results.

Outcome measures included: patient's age at diagnosis, gender, laterality, smoking, presenting symptoms and visual acuity at presentation. Evaluated tumor clinical characteristics included: tumor location, surface features, shape, thickness, largest basal diameter, size, pigmentation, presence of subretinal fluid, vitreous hemorrhage, cataract, neovascular glaucoma, rubeosis, MRI features, TNM staging, presence and site of metastasis. For tumors treated by brachytherapy, additional features included plaque size, apex dose, rate of radiation, distance between tumor's edge and the optic nerve and the fovea, tumor thickness and visual acuity after treatment.

Inclusion and Exclusion Criteria: The eligibility criteria for inclusion were eyes with clinical and/or pathologic diagnosis of intraocular uveal melanoma treated either by radioactive plaques or by enucleation.

Pathological Characteristics and Definitions: In this study, the tumors were classified according to the Collaborative Ocular Melanoma Study (COMS) classification. The COMS divided uveal melanomas based on size into small, medium and large tumors (9). Small melanoma; 5-16 $\mathrm{mm}$ at the largest basal diameter (LBD) and $1-3 \mathrm{~mm}$ in apical height. Medium-sized melanoma; $16 \mathrm{~mm}$ or less at the LBD and had an apical height between $3 \mathrm{~mm}$ and $10 \mathrm{~mm}$ and uveal melanomas more than $16.0 \mathrm{~mm}$ at the LBD and more than $10 \mathrm{~mm}$ in height were defined as large tumors. Pathologically; and according to the Callender Classification, mixed tumors have been defined as tumors that had less than $50 \%$ of cells as epithelioid in type, while epithelioid tumors are those with more than $50 \%$ of cells as epithelioid in type $(10,11)$. TNM staging was according to the 7th edition of the American Joint Committee on Cancer (AJCC) staging system (12).

Reviewed data from the medical records regarding treatment included the following: complications of brachytherapy, and histopathological features of enucleated eyes. The histopathology was further reviewed regarding extraocular extension of the tumor such as extrascleral and/or optic nerve involvement at the time of enucleation.

Follow-up of these patients was documented including period, evidence of metastasis and patient status during the period of the follow-up.
In our center, indications for enucleation included a tumor involving or touching the optic nerve, large-sized tumor, recurrence of tumor after brachytherapy, associated total retinal detachment and secondary neovascular glaucoma (NVG).

\section{RESULTS}

Seventy-six eyes were diagnosed with uveal melanoma in King Hussein Cancer Center (KHCC) between July 2006 and April 2014. Thirty patients were excluded from the data analysis because of inadequate data and/or because the patients refused treatment and were lost for follow up.

Demographics and clinical features: 46 eyes with uveal melanoma from 46 patients were studied. The mean age at diagnosis was 46 years (median 45 years, range; 1.5-75 years,). There were $21(45 \%)$ males and all (100\%) patients had single tumor. Eighteen (39\%) eyes were treated by primary enucleation, and $28(61 \%)$ eyes were treated by I-125 radioactive plaque therapy. Two of the eyes treated by plaque therapy were consecutively enucleated. Demographics are shown in Table I.

Tumor features: The melanoma was in the choroid in 40 (87\%) eyes, in the ciliary body in $6(13 \%)$ eyes, and no single patient had iris melanoma in this series. According to the 7th edition of the American Joint Committee on Cancer staging system (UICC/AJCC); 8 (17\%) were T1, $17(36 \%)$ were $\mathrm{T} 2,16(35 \%)$ were $\mathrm{T} 3$, and $5(11 \%)$ were T4. One (2\%) patient had lymph node metastasis (N1), and $5(11 \%)$ patients showed distant metastasis (M1). One patient already had metastasis at time of diagnosis while the others were discovered to have metastasis later after the diagnosis by an average interval of 26 months. Details of tumor features in both groups (enucleation and plaque group) are shown in Table II.

Pathologic features of enucleated eyes: A definitive diagnosis of uveal melanoma was confirmed by histopathology in 20(43\%) eyes after enucleation. On histopathological examination, $2(10 \%)$ tumors were spindle cell type uveal melanoma, 4 (20\%) tumors were epithelioid cell type, and $14(70 \%)$ tumors were of mixed type uveal melanoma (Figure 1A,B). Extrascleral extension was seen in $3(15 \%)$ eyes (Figure $1 \mathrm{C}$ ), and optic nerve invasion was seen in 2 (10\%) eyes.

Plaque features: The radioactive plaques used had a median size of $16 \mathrm{~mm}$ with a range between $12 \mathrm{~mm}$ and 20 $\mathrm{mm}$. The total radiation apex dose was $85 \mathrm{~Gy}$ in all patients (median radiation rate $=7.25$, range: 4.5 to 13 ). The main complications included 5 cases of cataract, 7 cases of NVG, 
Table I: Demographics and clinical features of the patients

\begin{tabular}{|l|l|c|c|c|c|c|c|}
\hline & & \multicolumn{2}{|c|}{ Enucleated Group } & \multicolumn{2}{c|}{ Plaque Group } & \multicolumn{2}{c|}{ Total Group } \\
\hline Number & & $20^{*}$ & $\%$ & 28 & $\%$ & 46 & $\%$ \\
\hline Age (Years) & Range & $1.5-67$ & & $21-75$ & & $1.5-75$ & \\
& Median & 45 & & 44 & & 45 \\
& Mean & 44 & & 48 & & 46 & \\
\hline Gender** & M & 6 & 30 & 16 & 57 & 21 & 46 \\
& F & 14 & 70 & 12 & 43 & 25 & 54 \\
\hline Side & Right & 6 & 30 & 11 & 39 & 19 & 41 \\
& Left & 14 & 70 & 17 & 61 & 27 & 59 \\
\hline Smoking & Yes & 7 & 35 & 8 & 29 & 14 & 30 \\
& No & 13 & 65 & 20 & 71 & 32 & 70 \\
\hline Presenting symptom & Impaired vision & 18 & 90 & 20 & 71 & 36 & 87 \\
& Accidental & 0 & 0 & 5 & 18 & 5 & 11 \\
& Others*** & 2 & 10 & 3 & 11 & 5 & 11 \\
\hline Visual acuity at presentation & $>=0.5$ & 2 & 10 & 14 & 50 & 16 & 35 \\
& $0.1-0.4$ & 5 & 25 & 9 & 32 & 13 & 28 \\
& $<0.1$ & 13 & 65 & 5 & 18 & 17 & 37 \\
\hline
\end{tabular}

${ }^{\star} 18$ eyes were primarily enucleated and 2 eyes were enucleated after failure of salvage by radioactive plaque. ${ }^{\star *} \mathbf{M}=$ Male, $\mathrm{F}=\mathrm{Female}$. *** Others included: floaters, wondering eyes
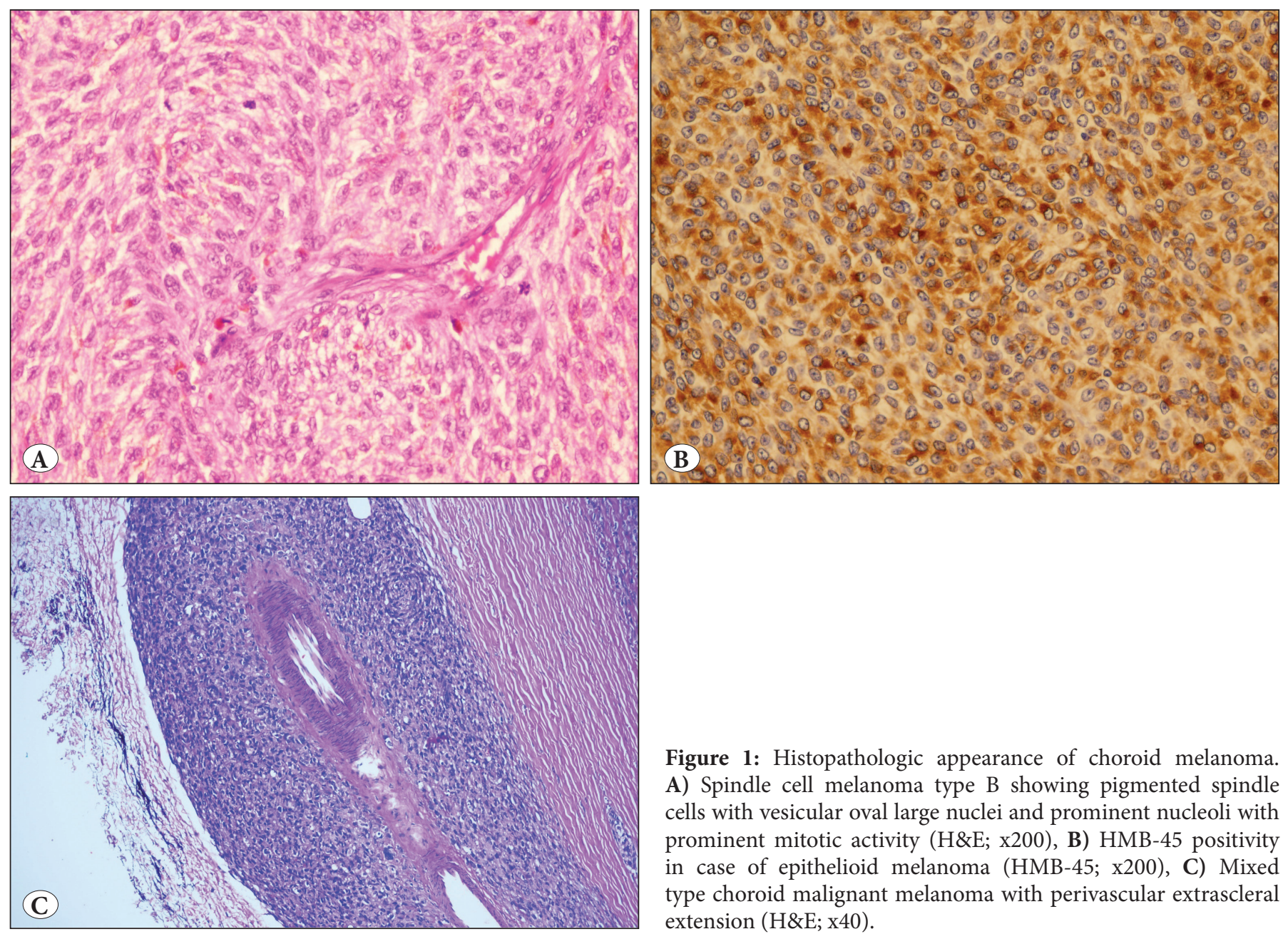

Figure 1: Histopathologic appearance of choroid melanoma. A) Spindle cell melanoma type B showing pigmented spindle cells with vesicular oval large nuclei and prominent nucleoli with prominent mitotic activity (H\&E; x200), B) HMB-45 positivity in case of epithelioid melanoma (HMB-45; x200), C) Mixed type choroid malignant melanoma with perivascular extrascleral extension (H\&E; x40). 
Table II: The characteristics of the tumors

\begin{tabular}{|c|c|c|c|c|c|c|c|}
\hline \multirow{2}{*}{\begin{tabular}{|l} 
\\
Number
\end{tabular}} & & \multicolumn{2}{|c|}{ Enucleated Group } & \multicolumn{2}{|c|}{ Plaque Group } & \multicolumn{2}{|c|}{ Total Group } \\
\hline & & $20^{*}$ & $\%$ & 28 & $\%$ & 46 & $\%$ \\
\hline \multirow[t]{3}{*}{ Site } & Choroid & 19 & 95 & 23 & 82 & 40 & 78 \\
\hline & Ciliary body & 1 & 5 & 5 & 18 & 6 & 13 \\
\hline & Iris & 0 & 0 & 0 & 0 & 0 & 0 \\
\hline \multirow[t]{2}{*}{ Shape } & Dome & 18 & 90 & 26 & 93 & 42 & 91 \\
\hline & Mushroom & 2 & 10 & 2 & 7 & 4 & 7 \\
\hline \multirow[t]{3}{*}{ Thickness at diagnosis } & $>10$ & 11 & 55 & 4 & 14 & 13 & 28 \\
\hline & $5-10$ & 9 & 45 & 18 & 65 & 27 & 59 \\
\hline & $<5$ & 0 & 0 & 6 & 21 & 6 & 13 \\
\hline \multirow[t]{3}{*}{ Largest basal diameter } & $<5$ & 0 & 0 & 0 & 0 & 0 & 0 \\
\hline & $5-16$ & 15 & 75 & 28 & 100 & 39 & 85 \\
\hline & $>16$ & 5 & 25 & 0 & 0 & 7 & 15 \\
\hline \multirow[t]{3}{*}{ Size } & Small & 0 & 0 & 1 & 4 & 1 & 2 \\
\hline & Medium & 3 & $\begin{array}{l}15 \\
85\end{array}$ & 20 & 71 & 24 & 52 \\
\hline & Large & 17 & & 7 & 25 & 21 & 46 \\
\hline \multirow[t]{2}{*}{ Pigmentation } & Melanotic & 19 & 95 & 26 & 93 & 43 & 93 \\
\hline & Amelanotic & 1 & 5 & 2 & 7 & 3 & 7 \\
\hline \multirow[t]{4}{*}{ T-stage } & $\mathrm{T} 1$ & 0 & 0 & 8 & 29 & 8 & 17 \\
\hline & $\mathrm{T} 2$ & 8 & 40 & 10 & 36 & 17 & 37 \\
\hline & $\mathrm{T} 3$ & 8 & 40 & 9 & 32 & 16 & 35 \\
\hline & $\mathrm{T} 4$ & 4 & 20 & 1 & 3 & 5 & 11 \\
\hline \multirow[t]{2}{*}{ N-stage } & N0 & 20 & 100 & 27 & 96 & 45 & 98 \\
\hline & N1 & 0 & 0 & 1 & 4 & 1 & 2 \\
\hline \multirow[t]{2}{*}{ M-stage } & M0 & 18 & 90 & 25 & 89 & 41 & 89 \\
\hline & M1 & 2 & 10 & 3 & 11 & 5 & 11 \\
\hline \multirow[t]{5}{*}{ Associated features ${ }^{\star *}$} & Subretinal fluid & 17 & 85 & 17 & 61 & 32 & 70 \\
\hline & Vitreous hemorrhage & 6 & 30 & 5 & 18 & 10 & 22 \\
\hline & Glaucoma & 1 & 5 & 2 & 7 & 3 & 7 \\
\hline & Cataract & 2 & 10 & 5 & 18 & 7 & 15 \\
\hline & Orange Pigments & 17 & 85 & 25 & 89 & 40 & 87 \\
\hline
\end{tabular}

${ }^{\star} 2$ Eyes were enucleated after failure of salvage by radioactive plaque. ${ }^{\star *}$ Some patients had multiple associated features.

1 case of recurrence, 1 case of radiation optic neuropathy, and 5 cases of radiation retinopathy. At last follow up after therapy, tumor thickness was $<5 \mathrm{~mm}$ in 13 (46\%)eyes, and $5-10 \mathrm{~mm}$ in 13 (46\%) eyes. The median tumor thickness after therapy was $4.5 \mathrm{~mm}$ (range; $2-8 \mathrm{~mm}$ ), and the decrease in tumor thickness was variable between the treated eyes (Table III). Two eyes were consecutively enucleated; one for tumor recurrence, and one for uncontrolled painful NVG. After therapy, visual acuity was equal or better than 0.5 in 11 (42\%) eyes, 0.1-0.4 in 5 (19\%) eyes, and less than 0.1 in $10(38 \%)$ eyes. 2 (7\%) eyes had better vision while 15 (54\%) eyes had worse vision after treatment.
Outcome and follow up: Twenty eyes were enucleated; 17 (85\%) eyes were large (more than $16.0 \mathrm{~mm}$ at the LBD and more than $10 \mathrm{~mm}$ in height), 17 (85\%) eyes had RD, 1 (5\%) eye had tumor recurrence after plaque therapy, 2 (10\%) eyes had neovascular glaucoma, and $2(10 \%)$ tumors were touching the optic nerve. Three (15\%) patients required additional external beam radiation post enucleation due to extraocular tumor extension confirmed pathologically. At a median follow up of 24 months in the plaque group, 26 eyes were salvaged while 2 eyes have been enucleated.

Five patients out of 46 patients (11\%) included in our series had metastasis ( 5 had liver metastasis, 1 had lung 
Table III: The final outcome of the patients

\begin{tabular}{|c|c|c|c|c|c|c|c|}
\hline \multirow[b]{2}{*}{ Number } & & \multicolumn{2}{|c|}{ Enucleated Group } & \multicolumn{2}{|c|}{ Plaque Group } & \multicolumn{2}{|c|}{ Total Group } \\
\hline & & $20^{*}$ & $\%$ & 28 & $\%$ & 46 & $\%$ \\
\hline \multirow[t]{3}{*}{ Change in tumor thickness } & $<30 \%$ & $\mathrm{NA}^{\star *}$ & & 10 & 36 & NA & \\
\hline & $30-50 \%$ & NA & & 9 & 32 & NA & \\
\hline & $>50 \%$ & NA & & 7 & 25 & & \\
\hline \multirow[t]{3}{*}{ Change in visual acuity } & Stable & NA & & 8 & 29 & NA & \\
\hline & Better & NA & & 2 & 7 & NA & \\
\hline & Worse & NA & & 15 & 54 & NA & \\
\hline \multirow[t]{2}{*}{ Salvage } & Yes & NA & & 26 & 93 & 26 & 57 \\
\hline & No & NA & & 2 & 7 & 20 & 43 \\
\hline \multirow[t]{2}{*}{ Metastasis } & Yes & 2 & 10 & 3 & 11 & 5 & 11 \\
\hline & No & 18 & 90 & 25 & 89 & 41 & 89 \\
\hline \multirow[t]{2}{*}{ Alive } & Yes & 19 & 95 & 26 & 93 & 43 & 96 \\
\hline & No & 1 & 5 & 2 & 7 & 3 & 4 \\
\hline $\mathrm{F} / \mathrm{U}^{* * *}$ & $\begin{array}{l}\text { Range (years) } \\
\text { Median } \\
\text { Mean } \\
\end{array}$ & $\begin{array}{c}0.5-6 \\
2 \\
2.45 \\
\end{array}$ & & $\begin{array}{c}0.5 \text { to } 5 \\
2 \\
2.18 \\
\end{array}$ & & $\begin{array}{c}0.5 \text { to } 6 \\
2 \\
2.26 \\
\end{array}$ & \\
\hline
\end{tabular}

* 2 Eyes were enucleated after failure of salvage by radioactive plaque. ${ }^{* *}$ NA: Not Applicable. ${ }^{* * *} \mathrm{~F} / \mathrm{U}=$ Follow up.

metastasis, 1 had lymph nodes metastasis and 1 had bone metastasis). 3 patients had plaque therapy and the other 2 underwent enucleation (one found to have epithelioid cell type and the other mixed cell type). 2 patients had a large-sized tumor, all tumors located in the choroid, and 3 patients were dead from the metastasis at the last date of follow up after an average of 30 months from time of diagnosis. Details of outcome in enucleation and plaque groups are shown in Table III.

\section{DISCUSSION}

Well-developed data about uveal melanoma in the Middle East is missing except in the form of small local case series and case reports. Our series showed 77 cases of uveal melanoma documented between 2006 and 2014 in a tertiary cancer center in Jordan, and this low number provides the impression that uveal melanoma occurs with a low frequency in our region. In Saudi Arabia, one study showed only 40 cases of uveal melanoma diagnosed between 1983 and 2005, only 28 of them were of Saudi Arabian ancestry (13). Similarly, another report from the Shanghai Eye, Ear, Nose and Throat Hospital in China showed only 103 cases of uveal melanoma diagnosed between 1955 and 1979 (14). On the other hand, 688 cases of uveal melanoma were diagnosed among New York State residents between 1975 and 1986 (15), and similarly, 2997 patients had been registered to have uveal melanomas in Sweden during the period from 1960 to 1998 (16). Even statistics about the incidence of uveal melanoma in the Middle East and most of the developing countries are missed, it seems that the incidence in the Middle East and in Asia is less than the incidence of uveal melanoma in USA and Europe.

This wide variation in incidence can be attributed to the light skin color in USA and Europe residents which is one of the risk factors for developing this tumor.

The average age at diagnosis in this series was 46 years, while the average age at diagnosis in the COMS study was 60 years (17), which is 14 years older than the age at diagnosis in our series and 10 years more than in patients participating in a study performed in Saudi Arabia reporting an average age at 50 years (13). The reasons for younger age of incidence in our patients are not known. There was a slight, statistically insignificant, predominance of females in our retrospective study, in contrary to most reported studies that showed male predominance (18-21). This difference may be due to the low number of patients in our series. However, no sex predilection was found in the COMS randomized prospective study (6).

In our review, a significant percentage (65\%) of affected eyes had a visual acuity of less than 0.1 , which is worse than the visual acuity for of patients studied in the COMS study where only $33 \%$ had visual acuity of less than 0.1 (9). This finding might be explained by the delay in presentation 
after the onset of ocular complaints in developing poor countries where health care could be unachievable because of the high cost or of far distance to travel.

Most (70\%) of our patients who underwent enucleation had the mixed cell type melanoma, $20 \%$ had the epithelioid cell type, and $10 \%$ had the spindle cell type, which is almost similar to COMS findings where $86 \%$ were of the mixed cell type (22). This indicates that melanoma in our community is pathologically similar to the west.

In the COMS study, the estimated melanoma-related mortality was $1 \%$ at 5 years and was $4 \%$ at 8 years for patients with small melanomas (23). 5-year melanomarelated mortality, based on histopathologically confirmed metastasis, increased to $10 \%$ for patients with mediumsized tumors, and to $28 \%$ for patients with large tumors (24). The delay in presentation to our institution likely played a major role in finding a significant number of patients (about 98\%) with medium and large uveal melanomas. Due to the short follow-up period available (median of 24 months), it was difficult to determine the survival outcome among our patient population. Of the 5 patients who had metastasis in this series, 3 patients had medium sized tumors and 2 patients had large sized tumors. In the COMS, the liver was the predominant site of metastasis, which was reported in $89 \%$ of metastatic patients (25). Our study showed metastasis in only $11 \%$ of patients and in all the liver was involved.

It can be concluded that the incidence of uveal melanomas in our region is low compared to that in the West. A significant number of Arabic patients, unfortunately, present to ocular oncology clinics at a time where the tumor reaches a large size or is associated with complications that make it non-amenable for brachytherapy and end up with enucleation. Therefore, awareness must be increased and early detection improved with prompt referral by the general ophthalmologist to save more eyes and to enhance survival of affected patients. This study was retrospective, so the follow-up was limited after treatment. It is recommended to perform larger, multicenter and longer term follow-up studies with more emphasis on accurate and detailed gathering of information from the patients before and after treatment in addition to comprehensive clinical and investigational exams to determine the true incidence and predisposing risk factors in addition to improving statistical data on uveal melanomas in our region.

\section{ACKNOWLEDGEMENTS}

We acknowledge the support of the Eye Cancer Foundation Inc. (New York, NY USA, http://eyecancerfoundation.net) for Dr. Zewar for the Ocular Oncology Fellowship.

\section{CONFLICT OF INTEREST}

The authors declared no conflict of interest.

\section{FUNDING SOURCE}

The authors declared no funding source was involved in the creation of this manuscript.

\section{REFERENCES}

1. Finger PT. Intraocular melanoma. In: Devita VT, Lawrence TS, Rosenberg SA, editors. Cancer (principles \& practice of oncology) Ophthalmology. 10th ed. Philadelphia: LWW; 2011. 1770-9.

2. Shields CL, Kaliki S, Furuta M, Mashayekhi A, Shields JA. Clinical spectrum and prognosis of uveal melanoma based on age at presentation in 8,033 cases. Retina. 2012;32:1363-72.

3. Shields CL, Kaliki S, Shah SU, Luo W, Furuta M, Shields JA. Iris melanoma: Features and prognosis in 317 children and adults. J AAPOS. 2012;16:10-6.

4. Oittinen HA, O'Shaughnessy M, Cullinane AB, Keohane C. Malignant melanoma of the ciliary body presenting as extraocular metastasis in the temporalis muscle. J Clin Pathol. 2007;60:834-5.

5. Kujala E, Makitie T, Kivela T. Very long-term prognosis of patients with malignant uveal melanoma. Invest Ophthalmol Vis Sci. 2003;44:4651-9.

6. Diener-West M, Earle JD, Fine SL, Hawkins BS, Moy CS, Reynolds SM, Schachat AP, Straatsma BR; Collaborative Ocular Melanoma Study Group. The COMS randomized trial of iodine 125 brachytherapy for choroidal melanoma, III: Initial mortality findings. COMS Report No. 18. Arch Ophthalmol. 2001;119:96982.

7. Singh AD, Kalyani P, Topham A. Estimating the risk of malignant transformation of a choroidal nevus. Ophthalmology. 2005;112:1748-9.

8. Collaborative Ocular Melanoma Study Group. The COMS randomized trial of iodine 125 brachytherapy for choroidal melanoma: V. Twelve-year mortality rates and prognostic factors: COMS report No. 28. Arch Ophthalmol. 2006;124:168493.

9. Singh $\mathrm{AD}$, Kivelä $\mathrm{T}$. The collaborative ocular melanoma study. Ophthalmol Clin North Am. 2005;18:129-42.

10. Accuracy of diagnosis of choroidal melanomas in the Collaborative Ocular Melanoma Study. COMS report no. 1. Arch Ophthalmol. 1990;108:1268-73.

11. Albert DM, Ruzzo MA, McLaughlin MA, Robinson NL, Craft JL, Epstein J. Establishment of cell lines of uveal melanoma. Methodology and characteristics. Invest Ophthalmol Vis Sci. 1984;25:1284-99. 
12. The AJCC Ophthalmic Oncology Task Force. Malignant melanoma of the uvea. In: Edge SE, Byrd DR, Carducci MA, Compton CA, editors. AJCC cancer staging manual. 7th ed. New York: Springer; 2009. 547-53.

13. Alsuhaibani AH. Uveal melanoma in the Saudi Arabian population: Two decades of management at the King Khaled Eye Specialist Hospital. Saudi J Ophthalmol. 2009;23:157-63.

14. Kuo PK, Puliafito CA, Wang KM, Liu HS, Wu BF. Uveal melanoma in China. Int Ophthalmol Clin. 1982;22:57-71.

15. Manschot WA, van Strik R. Uveal melanoma: Therapeutic consequences of doubling times and irradiation results. A review. Int Ophthalmol. 1992;16:91-9.

16. Bergman L, Seregard S, Nilsson B, Ringborg U, Lundell G, Ragnarsson-Olding B. Incidence of uveal melanoma in Sweden from 1960 to 1998. Invest Ophthalmol Vis Sci. 2002;43:2579-83.

17. Diener-West M, Earle JD, Fine SL, Hawkins BS, Moy CS, Reynolds SM, Schachat AP, Straatsma BR; Collaborative Ocular Melanoma Study Group. The COMS randomized trial of iodine 125 brachytherapy for choroidal melanoma, II: Characteristics of patients enrolled and not enrolled. COMS Report No. 17. Arch Ophthalmol. 2001;119:951-65.

18. McLean IW. Uveal nevi and malignant melanoma. In: Spencer WH, editor. Ophthalmic pathology: An atlas and textbook, 4th ed. Philadelphia: Saunders; 1996. 2121-217.

19. Barr CC, McLean IW, Zimmerman LE. Uveal melanoma in children and adolescents. Arch Ophthalmol. 1981;99:2133-6.
20. Scotto J, Fraumeni JF Jr, Lee JA. Melanomas of the eye and other noncutaneous sites: Epidemiologic aspects. J Natl Cancer Inst. 1976;56:489-91.

21. Phillpotts BA, Sanders RJ, Shields JA, Griffiths JD, Augsburger JA, Shields CL. Uveal melanomas in black patients: A cases series and comparative review. J Natl Med Assoc. 1995;87:709-14.

22. McLean IW, Foster WD, Zimmerman LE, Gamel JW. Modifications of Callender's classification of uveal melanoma at the Armed Forces Institute of Pathology. Am J Ophthalmol. 1983;96:502-9.

23. The Collaborative Ocular Melanoma Study Group. Mortality in patients with small choroidal melanoma: COMS Report No. 4. Arch Ophthalmol. 1997;115:886-93.

24. The Collaborative Ocular Melanoma Study (COMS) randomized trial of preenucleation radiation of large choroidal melanoma. II. Initial mortality findings. COMS Report No. 10. Am J Ophthalmol. 1998;125:779-96.

25. Diener-West M, Reynolds SM, Agugliaro DJ, Caldwell R, Cumming K, Earle JD, Green DL, Hawkins BS, Hayman J, Jaiyesimi I, Kirkwood JM, Koh WJ, Robertson DM, Shaw JM, Thoma J; Collaborative Ocular Melanoma Study Group Report 23. Screening for metastasis from choroidal melanoma: The Collaborative Ocular Melanoma Study Group Report No. 23. J Clin Oncol. 2004;22:2438-44. 